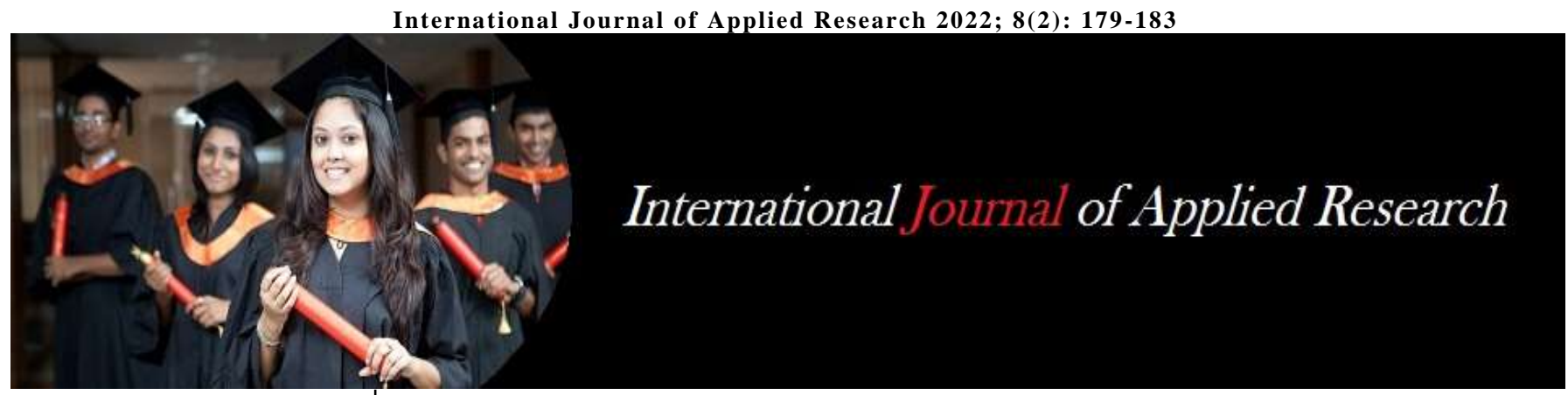

ISSN Print: 2394-7500

ISSN Online: 2394-5869

Impact Factor: 8.4

IJAR 2022; 8(2): 179-183

www.allresearchjournal.com

Received: 15-12-2021

Accepted: 18-01-2022

Samuel Kofi Donkor

Ph.D. (Lead Author),

Department of Physical

Education and Sport Studies,

School of Education and

Leadership, University of

Ghana, Legon-Accra, Ghana

Reginald Ocansey

Professor, Department of

Physical Education and Sport

Studies, School of Education

and Leadership, University of

Ghana, Legon-Accra, Ghana

Corresponding Author:

Samuel Kofi Donkor

Ph.D. (Lead Author)

Department of Physical

Education and Sport Studies,

School of Education and

Leadership, University of

Ghana, Legon-Accra, Ghana

\section{Physical education programme in public primary schools: Analysis of engagement time of pupils in six selected educational circuits}

\author{
Samuel Kofi Donkor and Reginald Ocansey
}

DOI: https://doi.org/10.22271/allresearch.2022.v8.i2c.9433

\section{Abstract}

Cross sectional survey was used to assess engagement time for teaching and learning PE content in a typical school week in public primary schools. Subjects were 172 out of estimated population of 300 in six randomly sampled educational circuits. Validated and reliable self-structured questionnaire was used for data collection. Pre-data analyses were performed to clean data from probable errors during data entering. All data were analyzed using Statistical Package for Social Sciences (SPSS for Windows, Version 17). The study found that the average engagement time of pupils in physical education programme in a typical school week was less than $50 \%$ of the total allocated time prescribed on the school time table for public primary schools. Statistically, the study revealed that male and female teachers in public primary schools did not significantly differ in terms of time spent teaching PE programme in a typical school week. Similarly, both upper and lower primary school teachers did not demonstrate statistically significant difference in engagement time of pupils in a typical school week.

Keywords: Engagement time, allocated time, active performing time, typical school week, PE programme

\section{Introduction}

Time is a critical element for high quality physical education (PE) programme in all educational settings. Primarily, teaching and learning cannot take place without time. Time waits for nobody and it is crucial that teachers manage the time resource efficiently to promote learning. For learning to occur, teachers must make attempt to increase engagement time of students in performing lesson objectives within the allocated time for the PE programme. However, earlier studies suggested that "many elementary students do not receive adequate time in PE class" (Turner, Johnson, Calvert \& Chaloupka, 2017, p.214) [20] and that some schools have reduced school-day time allocated for PE programme due to funding shortfalls for resources (Picus \& Odden, 2011) ${ }^{[15]}$. Time for learning PE content is categorized as allocated time, engaged time and active performing time. Allocated time refers to the time table period designated for the PE lesson. The time students spend in performing the lesson objectives denote engagement time which is part of the allocated time organized by the teacher to teach students with the goal to perform the lesson objectives. Active performing time refers to the actual amount of time students spend in making responses pertinent to the lesson objectives (Siedentop, 2004) ${ }^{[17]}$.

Research has demonstrated that above and beyond time, how students actually use time for individual practice and whether the practice is appropriate to their skill level is strongly related to skill development (Tyson \& Silverman, 1994) ${ }^{[21]}$. Notably, time engaged in learning is a significant predictor of academic achievement. According to literature "what the teacher does with the instructional allocated time is critical" (Fisher, 2009, p.169) ${ }^{[7]}$. When teachers structure time for practice and class is organized so students have a number of appropriate practice trials, it is highly likely they will progress and learn the skills being taught. In many situations, some teachers fail to provide time for children to take part actively in PE programmes. Sadly, in some schools, mandated PE periods are reduced or used for other things (Karbo, Ogah and Domfeh, 2011) ${ }^{[11]}$. In some instances, parents do not allow their children to take part in PE and sports activities. A situation like this is improper and does not depict decent education. 
It is worth noting that before the revision of PE syllabus in 2019, each public primary school was allocated four periods of 35 minutes for teaching and learning PE curriculum in a typical school week in Ghana. Presently, the physical and health subject in the primary schools of Ghana is allocated two periods of 30 minutes per week. So long as school curricular programme is concerned, time is to be regarded as a precious commodity for children to do various curricular activities within the PE programme.

Generally, schools are being held accountable for student learning time and PE is not exempt from this accountability (Lund \& Tannehill, 2014) ${ }^{[12]}$. Therefore, if physical educators are to keep the PE programme and make it viable, then time must be part of accountability process and teachers must be held accountable for time allocated for teaching mandatory PE programme in schools. In schools where time for teaching PE is not part of accountability process, heads and teachers cut time available for PE to do other things. But if PE would continue to be part of the school curriculum, teachers must find time to connect with the educational goals of their schools to meet physical activity needs of children in every educational setting.

\section{Purpose of the study}

The purpose of the study was to

1. Analyse the average engagement time of pupils in physical education programme for public primary schools.

2. Explore differences between male and female teachers in engagement time for teaching and learning the physical education programme in public primary schools.

3. Explore differences between lower and upper primary school teachers in engagement time for teaching and learning PE content in a typical school week.

\section{Method \\ Population}

The study targeted estimated population of 300 trained teachers $($ male $=183$, female $=117)$ in the public primary schools of six selected educational circuits. The age distribution of the study participants ranged from a minimum of 20 to a maximum of 57 years. All subjects for the study were employees of Ghana Education Service (GES) who could read, write and speak English language.

\section{Sampling}

Multistage sampling technique involving stratified sampling, simple random sampling and total population sampling yielded a sample of 172 subjects (male $=97$, female $=75$ ) for the study. Precisely, in the first stage of the sampling process, three geographical areas were stratified for the study. The strata were northern, central and southern geographical areas of the Volta Region, Ghana. In the northern geographical stratum, two out of eight educational circuits were randomly selected from the Kadjebi district. In the central geographical stratum, two out of 13 educational circuits were randomly selected from Ho West district. In the Southern geographical stratum, two out of six educational circuits were randomly selected from Akatsi North district. This yielded a total of six educational circuits as data collection sites for the study. The stratified geographical areas (northern, central and southern) distinctively stand out in PE and sports activities by the
Colleges of Education (CoE) in the Volta Region of Ghana. Total population sampling was the next stage of the sampling process. The total population sampling at this stage was due to small numbers of teachers for which each primary school within the selected educational circuits was estimated to have only six classroom teachers and that only six to 13 public primary schools were located in the educational circuits selected for the study.

\section{Instrumentation}

Using self-structured questionnaire, respondents provided answers relating to their background characteristics and the amount of time spent engaging pupils in PE programme in a typical school week. The data collection instrument was validated by three university instructors who possessed considerable experience in educational and social research. For reliability, an acceptable alpha level has conventionally been 0.70 or higher (Gay, Mills, Airasian, 2009). In the present study, Cronbach alpha reliability coefficient demonstrated a good reliability of the data collection instrument $(a \geq .71)$.

\section{Data collection procedures}

The study went through approval process for the acquisition of ethical clearance with ID number UCCIRB/CES/2016/14 granted by the Institutional Review Board (IRB) at the University of Cape Coast (UCC) in Ghana. Moreover, letter of introduction was granted by the head of Health, Physical Education and Recreation (HPER) department of UCC. Four research assistants were trained prior to data collection in each of the data collection sites. During the training session, research assistants were taken through the procedures and modalities for administering the questionnaires and how to carry out data entry using Statistical Package for Social Sciences (SPSS).

Week days were largely used for data collection within the educational circuits sampled for the study. Respondents were enlightened on the purpose of data collection and were encouraged to do independent work. These respondents were advised to complete the questionnaire during break periods (first and second breaks) to avoid interference with instructional hours. Respondents were also allowed to complete the items in the house and submit them to designated data collection coordinators (school heads or designated teachers) within one week of administration. Generally, collection of completed questionnaire took one week. In some instances, completed questionnaires were collected on spot. In all, 172 subjects appropriately completed the questionnaire which was used for data analyses.

\section{Data Analyses}

Analyses were conducted using Statistical Package for Social Science (SPSS for Windows 2007, Version 21). In the process, pre-data analyses were performed to identify and eliminate probable errors from the data set. Boxplots and Histograms were generated and examined for parametric assumptions relating to the use of independent samples t-test. Scores on the dependent variable (engagement time) were approximately normally distributed with no extreme outliers. Observation of scatterplot indicated that variances were homogenous.

Typically, teachers were to indicate the amount of time they spent engaging pupils in learning PE curriculum in a typical 
school week. Descriptive statistics (mean, percentage, standard deviation) were used to present results relating to the amount of time students were engaged in learning PE curriculum in a typical school week. However, t-test statistics were used to analyse gender differences and class level differences relating to engagement time for teaching and learning the PE programme in public primary schools.

\section{Results}

Analyses of demographic characteristics of subjects

Overall, 172 subjects participated in the study. From the data set, males $(n=97)$ were $56 \%$ and females $(n=75)$ were $44 \%$. Figure 1 presents analyses of gender distribution of study participants.

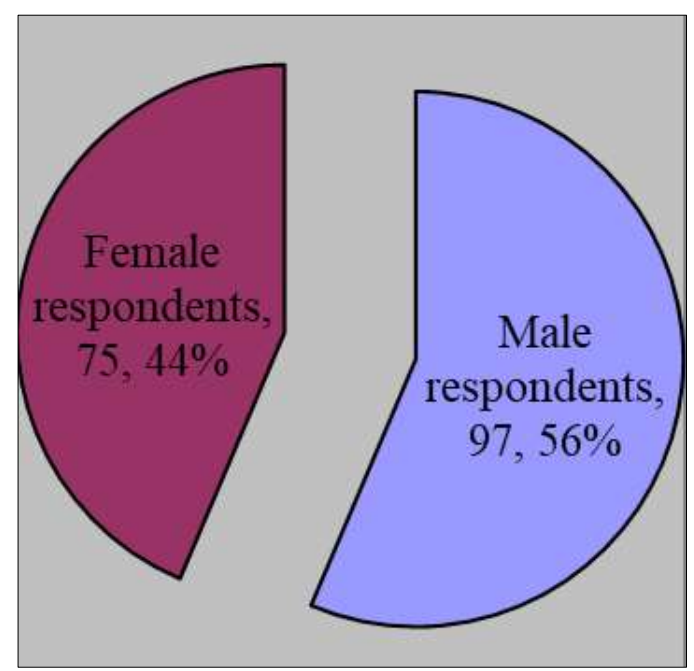

Fig 1: Gender distribution of study participants

According to demographic data, respondents drawn from lower primary schools were 28 classroom teachers $(16 \%)$, 26 classroom teachers (15\%), and 24 classroom teachers (14\%) who taught basic one, two and three respectively. In upper primary school, 31 classroom teachers (18\%), 34 classroom teachers (20\%), and 29 classroom teachers (17\%) were drawn from basic four, five and six respectively. Figure 2 presents class distribution of study participants.

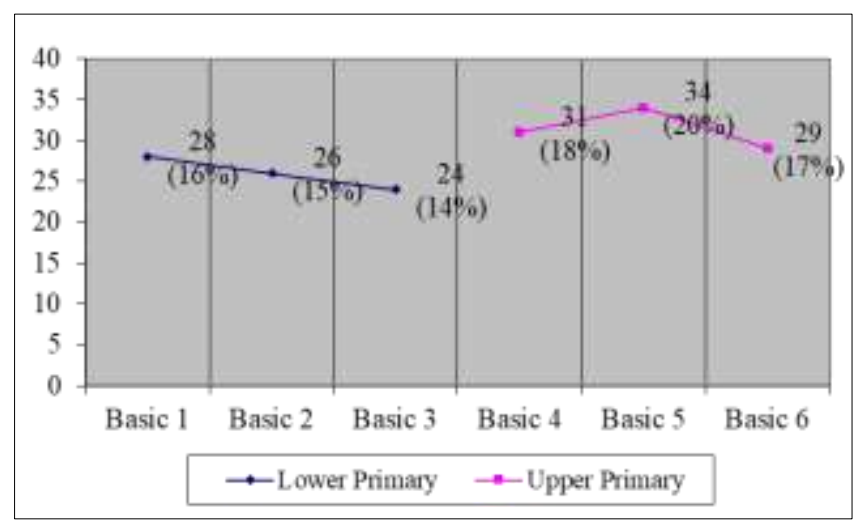

Fig 2: Class distribution of study participants

In terms of age distribution, 66 respondents (38\%) were aged 29 years or less, 50 respondents $(29 \%)$ were aged 3034 years, while 56 respondents $(33 \%)$ were aged 35 years or more. Figure 3 presents analysis of age distribution of subjects.

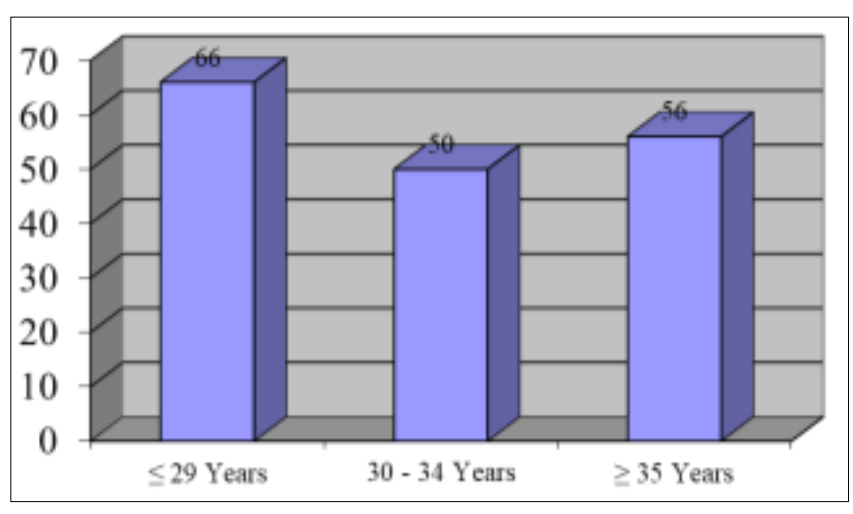

Fig 3: Age distribution of subjects

\section{Research question one}

What is the average engagement time of pupils in physical education programme for public primary schools?

Generally, the engagement time of pupils for PE programme in a typical school week was less than $50 \%$ of the total allocated time for PE lessons. In a typical school week, teachers in lower and upper primary schools engaged pupils for 40 minutes and 46 minutes respectively. Gender analysis of the engagement time of pupils shows that male and female teachers engaged pupils for 46 minutes and 38 minutes respectively in a typical school week. Teachers of various classes (primary class one to primary class six) could not maximize engagement time of pupils beyond 54 minutes out of 140 minutes allocated for teaching PE programme in public primary schools. Table 2 presents analyses of engagement time of pupils in a typical school week.

Table 2: Analyses of engagement time of pupils for physical education programme in a typical school week

\begin{tabular}{|c|c|c|c|}
\hline \multirow{2}{*}{ Respondents } & \multicolumn{3}{|c|}{ Out of 140 minutes allocated } \\
& \multicolumn{3}{|c|}{$\begin{array}{c}\text { Mean } \\
\text { time }\end{array}$} \\
\cline { 2 - 4 } & $\begin{array}{c}\text { Standard } \\
\text { Deviation } \\
\text { (SD) }\end{array}$ & $\begin{array}{c}\text { Percentage } \\
\text { of Engaged } \\
\text { Time (\%) }\end{array}$ \\
\hline Lower primary school teachers & 40 & 37.03 & 29 \\
\hline Upper primary school teachers & 46 & 43.47 & 33 \\
\hline Male primary school teachers & 46 & 39.28 & 33 \\
\hline Female primary school teachers & 38 & 41.22 & 27 \\
\hline Primary 1 teachers & 39 & 47.71 & 28 \\
\hline Primary 2 teachers & 54 & 45.56 & 39 \\
\hline Primary 3 teachers & 41 & 39.05 & 29 \\
\hline Primary 4 teachers & 45 & 37.81 & 32 \\
\hline Primary 5 teachers & 31 & 34.47 & 22 \\
\hline Primary 6 teachers & 47 & 36.85 & 34 \\
\hline
\end{tabular}

\section{Research question two}

Are there significant differences between male and female teachers in engagement time for teaching and learning the physical education programme in public primary schools? Analyses of data relating to engagement time for teaching and learning PE programme in public primary schools in a typical school week shows that the difference between male teachers $(\mathrm{M}=45.82, \quad \mathrm{SD}=39.28)$ and female teachers $(\mathrm{M}=38.40, \quad \mathrm{SD}=41.22)$ is not statistically significant $[\mathrm{t}(170)=1.203, \mathrm{P}=.23]$. Table 3 presents the results on the differences between male and female classroom teachers in engagement time for teaching and learning the PE programme in a typical school week in public primary schools. 
Table 3: Differences between male and female teachers in engagement time for teaching and learning the PE programme in a typical school week in public primary schools

\begin{tabular}{|c|c|c|c|c|c|c|c|}
\hline & Gender & $\mathbf{N}$ & Mean & SD & t-value & df & p-value \\
\hline \multirow{2}{*}{ Engagement Time in PE } & Male teachers & 97 & 45.82 & 39.28 & \multirow{2}{*}{1.203} & \multirow{2}{*}{170} & \multirow{2}{*}{.23} \\
\cline { 2 - 7 } & Female teachers & 75 & 38.40 & 41.22 & & & \\
\hline
\end{tabular}

Significant at $p<.05$

\section{Research question three}

Are there significant differences between lower and upper primary school teachers in engagement time for teaching and learning PE content in a typical school week?

Results obtained from independent samples t-test on the time spent teaching PE curriculum in a typical school week indicated that there is no statistically significant difference between upper primary school teachers $(\mathrm{M}=39.84$, $\mathrm{SD}=37.03)$ and lower primary school teachers $(\mathrm{M}=45.68$, $\mathrm{SD}=43.49) ; \mathrm{t}(170)=-.952, \mathrm{p}=.343$. Table 4 presents the results of the differences between upper and lower primary school teachers in engagement time of pupils for the PE programme in public primary schools.

Table 4: Differences between upper and lower primary school teachers in engagement time of pupils for the PE programme in public primary schools

\begin{tabular}{|c|c|c|c|c|c|c|c|}
\hline \multirow{3}{*}{ Engagement time in PE } & Class level & $\mathbf{N}$ & Mean & SD & t-value & Df & p-value \\
\cline { 2 - 8 } & Upper primary teachers & 91 & 39.84 & 37.03 & -.952 & 170 & .343 \\
\cline { 2 - 8 } & Lower primary teachers & 81 & 45.68 & 43.49 & & & \\
\hline
\end{tabular}

Significant at $p<.05$

\section{Discussion}

Findings from the study revealed that the average engagement time of pupils in PE programme in a typical school week was less than $50 \%$ of the total allocated time prescribed on the school time table for public primary schools. This suggested that teachers of public primary schools did not effectively utilize PE allocated time to engage children in meaningful physical activities. Yet, studies in the field of PE have identified school setting as an important ground for promoting the recommended daily level of PA among children and young people (Dobbins, Husson, DeCorby, \& LaRocca, 2013; Donkor \& Hormenu, 2021; Harris, Kuramoto, Schulzer, \& Retallack, 2009; Waters et al., 2011) ${ }^{[4,5,9,23]}$. Findings of the study also showed that there was no statistically significant differences between male and female primary school teachers in time spent teaching the PE programme in a typical school week. Both upper and lower primary school teachers did not show statistically significant differences in engagement time for teaching and learning PE in a typical school week. This meant that the PE engagement time for pupils in the upper primary school was almost the same as the engagement time of pupils in the lower primary school level. Notably, before the revision of primary school curriculum in 2019, PE was allocated 140 minutes per week (four periods consisting of 35 minutes spread over two days) in all primary schools in Ghana. Presently, the allocated time for physical and health education subject in the primary schools of Ghana is 60 minutes per week ( 2 periods consisting of 30 minutes spread over two days). However, the study revealed that out of 140 minutes allocated time for PE lessons, teachers on average taught only about 43 minutes with most of the classroom teachers indicating that they did not teach PE at all. This situation is troubling in the wake of many studies that prove physical inactivity as a leading risk factor for premature death and non-communicable diseases (Donkor, 2021; WHO, 2018) ${ }^{[5]}$. Conversely, regular engagement in school PE programme could have positive impact on children physical, mental and academic achievement (Pedersen et al., 2016; Singh, Uijtdewilligen, Twisk, van Mechelen, \& Chinapaw, 2012; Nyawornota et al., 2018; Strong et al., 2005). According to WHO (2010) ${ }^{[16,18,14]}$, children and young people aged 5-17 years should accumulate at least 60 minutes of moderate- to vigorous- intensity PA daily.
However, globally only a segment of school-aged children and youth attain this recommendation (Inchley et al., 2016; Kalman et al., 2015) ${ }^{[10]}$. This inadequate engagement of children in PE programmes is consistent with findings of current study on reduced engagement time of pupils in PE programme for public primary schools. Despite the challenges of implementation of many school programmes, the PE curriculum is key aspect of providing children with opportunity to be physically active for lifetime (Basch, 2001, Donkor, 2021; Donkor \& Hormenu, 2021) ${ }^{[5,6]}$, which leads to improved academic work (CDC, 2010) ${ }^{[3]}$.

Notably, education in Ghana emphasizes subjects like mathematics, science and English. Under pressure to find more time for these subjects, teachers of PE and heads of basic schools seem pressured to find more time by reducing or eliminating time for teaching PE programme. Research indicates that time spent in PE does not decrease learning in other school subjects (Trunddeau et al, 1998). Indeed, literature reports that regular PE programme during school day activity enhances student performance (Siedentop, 2004) ${ }^{[17]}$. There is a growing awareness that the PE needs of children and their development as physically educated people cannot be met without devoting more time to $\mathrm{PE}$ programme. Evidently, if $\mathrm{PE}$ is to find time outside the regular school schedules, it must do so by linking with community PA and sport programmes for children (Siedentop, 2004) ${ }^{[17]}$. Despite the fact that PE has over the years been part of primary school curriculum, there is still a continuing need for implementation research that focuses on how to translate and disseminate effective interventions into meaningful daily practice in schools (Antikainen \& Ellis, 2011; Austin, Bell, Caperchione, \& Mummery, 2011; Naylor et al., 2015) ${ }^{[1,2,13]}$. In this instance, heads of schools and physical educators must regard time as a critical variable in ensuring a high-quality $\mathrm{PE}$ programme in schools.

\section{Conclusions}

The engagement time for learning PE curriculum in the public primary schools is woefully inadequate. Both male and female classroom teachers could not demonstrate statistically significant differences in maximizing engagement time of pupils in a typical school week. 
Similarly, there is no statistically significant difference between upper and lower primary school teachers in terms of engagement time for teaching and learning PE programme in a typical school week.

\section{Recommendation}

We recommend that engagement time for learning $\mathrm{PE}$ curriculum should be vital part of accountability in teaching and learning process. Heads of basic schools should frequently demand accountability on engagement time from all teachers who have the primary responsibility to teach PE as a compulsory school subject in public primary schools. Heads of institutions should note that quality PE programme must strive for a well-developed PE programme in order to meet the minimum daily recommendations for participating in meaningful physical activity for health and wellbeing.

\section{Limitations}

Data was based on 2017 preliminary studies for full-scale investigation with representative data of entire Volta Region, Ghana. We make no claim of generalizability beyond the scope of current study. Nonetheless, standard processes were adopted in the entire process of current research.

\section{Declaration of Conflicting Interests}

We declare no conflict of interest with respect to the conduct of this investigation, authorship and publication of this article.

\section{References}

1. Antikainen I, Ellis R. A RE-AIM evaluation of theorybased physical activity interventions. Journal of sport and exercise psychology. 2011;33(2):198-214.

2. Austin G, Bell T, Caperchione C, Mummery WK. Translating research to practice: using the RE-AIM framework to examine an evidence-based physical activity intervention in primary school settings. Health promotion practice. 2011;12(6):932-941.

3. Basch CE. Healthier students are better learners: high-quality, strategically planned, and effectively coordinated school health programs must be a fundamental mission of schools to help close the achievement gap. Journal of School Health. 2011;81(10):650-662.

4. Dobbins M, Husson H, DeCorby K, LaRocca RL, School-based physical activity programs for promoting physical activity and fitness in children and adolescents aged 6 to 18. Cochrane database of systematic reviews, 2013, (2).

5. Donkor SK. Adequacy of pre-service teacher education for teaching physical education curriculum in public primary schools: A study of teachers from six selected educational circuits. International Journal of Physiology, Nutrition and Physical Education. 2021;6(2):259-264.

6. Donkor SK, Hormenu T. Teacher-related barriers to effective teaching of physical education in public primary schools. International Journal of Physiology, Nutrition and Physical Education. 2021;6(2):330-335.

7. Fisher D. The use of instructional time in the typical high school classroom. The Educational Forum. 2009;73(2):168-176.

8. Gray LGE Mills, Airasian P. Educational Research: Competencies for Analysis and Applications. New Jersey: Pearson, 2009.
9. Harris KC, Kuramoto LK, Schulzer M, Retallack JE. Effect of school-based physical activity interventions on body mass index in children: A meta-analysis. Cmaj. 2009;180(7):719-726.

10. Inchley J, Currie D, Young T, Samdal O, Torsheim T, Augustson L, Weber M. Health behaviour in schoolaged children (HBSC) study: International Report from the 2013/2014 survey. Health policy for children and adolescents. 2016;7:1-277.

11. Karbo J, Ogah J, Domfeh D. An introduction to physical education. Cape Coast: CCE Publications, 2011.

12. Lund J, Tannehill D. Standards-based physical education curriculum development. Burlingto, Massachusetts: Jones \& Bartlett Publishers, 2014.

13. Naylor PJ, Nettlefold L, Race D, Hoy C, Ashe MC, Higgins JW, et al. Implementation of school based physical activity interventions: a systematic review. Preventive medicine. 2015;72:95-115.

14. Nyawornota VK, Luguterah A, Sofo S, Aryeetey R, Badasu M, Nartey J, et al. Results from Ghana's 2018 report card on physical activity for children and youth. Journal of Physical Activity and Health. 2018;15(s2):S366-S367.

15. Picus LO, Odden AR. Reinventing school finance: Falling forward. Peabody Journal of Education. 2011;86(3):291-303.

16. Pedersen HK, Gudmundsdottir V, Nielsen HB, Hyotylainen T, Nielsen T, Jensen BA, et al. Human gut microbes impact host serum metabolome and insulin sensitivity. Nature. 2016;535(7612):376-381.

17. Siedentop D. Introduction to physical education, fitness and sports. New York: The McGraw-Hill, 2004.

18. Singh A, Uijtdewilligen L, Twisk JW, Van Mechelen W, Chinapaw MJ. Physical activity and performance at school: a systematic review of the literature including a methodological quality assessment. Archives of pediatrics \& adolescent medicine. 2012;166(1):49-55.

19. Strong WB, Malina RM, Blimkie CJ, Daniels SR, Dishman RK, Gutin B, et al. Evidence based physical activity for school-age youth. The Journal of pediatrics. 2005;146(6):732-737.

20. Turner L, Johnson TG, Calvert HG, Chaloupka FJ. Stretched too thin? The relationship between insufficient resource allocation and physical education instructional time and assessment practices. Teaching and Teacher Education. 2017;68:210-219.

21. Tyson L, Silverman S. A detailed analysis of statewide teacher appraisal scores. Journal of Personnel Evaluation in Education. 1994;8(4):377-400.

22. US Department of Health and Human Services. Centers for disease control and prevention 2010. The association between school-based physical activity, including physical education, and academic performance, 2013.

23. Waters E, de Silva-Sanigorski A, Burford BJ, Brown T, Campbell KJ, Gao Y, et al. Interventions for preventing obesity in children. Cochrane database of systematic reviews, 2011, (12).

24. World Health Organization. Noncommunicable diseases country profiles 2018. Geneva: WHO, 2018. 